\title{
EFFECT OF LIGHT CURING UNIT ON RESIN-MODIFIED GLASS-IONOMER CEMENTS: A MICROHARDNESS ASSESSMENT
}

\author{
Daniela Francisca Gigo CEFALY ${ }^{1}$, Liliam Lucia Carrara Paes de MELLO ${ }^{2}$, Linda WANG ${ }^{3}$, \\ José Roberto Pereira LAURIS ${ }^{4}$, Paulo Henrique Perlatti D’ALPINO ${ }^{5}$
}

\author{
1- DDS, MSc, PhD, Associate Professor, Department of Operative Dentistry, University North of Paraná, Londrina, PR, Brazil. \\ 2- DDS, MSc, Associate Professor, Department of Operative Dentistry, North of Paraná Deontological Association, Londrina, PR, Brazil. \\ 3- DDS, MSc, PhD, Assistant Professor, Department of Operative Dentistry, Endodontics and Dental Materials, Bauru School of Dentistry, University \\ of São Paulo, Bauru, SP, Brazil. \\ 4- DDS, MSc, PhD, Associate Professor, Department of Pediatric Dentistry, Orthodontics and Community Health., Bauru School of Dentistry, University \\ of São Paulo; Bauru, SP, Brazil. \\ 5- DDS, MSc, PhD, Assistant Professor, Department of Operative Dentistry, University Bandeirante of São Paulo (UNIBAN Brazil), São Paulo, SP, \\ Brazil. \\ Corresponding address: Daniela Francisca Gigo Cefaly - Rua Antônio Rodrigues Cajado - ap. 103 - Vila Monteiro - 13560-291 - São Carlos, SP, Brasil. \\ Phone: +55 1631161370 - e-mail: dcefaly@uol.com.br \\ Received: March 12, 2008 - Modification: August 31, 2008 - Accepted: September 21, 2008
}

\begin{abstract}
$O$

bjective: To evaluate the microhardness of resin-modified glass-ionomer cements (RMGICs) photoactivated with a blue lightemitting diode (LED) curing light. Material and Methods: Thirty specimens were distributed in 3 groups: Fuji II LC Improved/GC (RM1), Vitremer/3M ESPE (RM2) and Filtek Z250/3M ESPE (RM3). Two commercial light-curing units were used to polymerize the materials: LED/Ultrablue IS and a halogen light/XL3000 (QTH). After 24 h, Knoop microhardness test was performed. Data were submitted to three-way ANOVA and Tukey's test at a pre-set alpha of 0.05 . Results: At the top surface, no statistically significant difference $(\mathrm{p}>0.05)$ in the microhardness was seen when the LED and QTH lights were used for all materials. At the bottom surface, microhardness mean value of RM2 was significantly higher when the QTH light was used $(p<0.05)$. For RM1, statistically significant higher values $(p<0.05)$ were seen when the LED light was used. No statistically significant difference $(p>0.05)$ was seen at the bottom surface for RM3, irrespective of the light used. Top-to-bottom surface comparison showed no statistically significant difference ( $>0.05$ ) for both RMGICs, regardless of the light used. For RM3, microhardness mean value at the top was significantly higher $(\mathrm{p}<0.05)$ than bottom microhardness when both curing units were used. Conclusion: The microhardness values seen when a LED light was used varied depending on the restorative material tested.
\end{abstract}

Key words: Glass-ionomer cements. Microhardness. Light-curing units.

\section{INTRODUCTION}

Quartz-tungsten-halogen lights (QTH) are the most frequently used curing units to photoactivate resin-based dental materials ${ }^{1,3,22}$. Benefits include the ability to polymerize all restorative materials, irrespective of the photoinitiator added ${ }^{20}$. Another advantage also includes a low-cost technology curing unit ${ }^{22}$. On the other hand, these light units develop high temperatures and have a declining power density over time due to bulb and filter aging ${ }^{17}$.

Advances in the light curing area have been remarkably seen, mainly after the development of the blue light-emitting diodes lights (LED) for photoactivation of resin composites $^{18}$. These devices are composed of solid-state LEDs that use junctions of doped semiconductors based on gallium nitride to directly emit light in the blue region of the spectrum, without excessive heating ${ }^{13}$. LED curing units are very compact, promise unlimited life ${ }^{23}$, working at reduced voltage. In addition, these curing units do not require filters to limit the wavelength range and the light emitted is very specific for the camphorquinone/amine system ${ }^{27}$.

Since the introduction of LED, studies have investigated the influence of these lights on the mechanical properties of resin-based restorative materials ${ }^{2,4,8,12,26}$. However, few studies are found in literature regarding the influence of LED lights on the mechanical properties of resin-modified glass ionomer cements (RMGIC) and compomers ${ }^{5,19}$. RMGIC have been defined as glass-ionomer cements that are modified by the inclusion of resin monomers ${ }^{18}$. In these materials, visible light curing of double bonds is coupled 
with the polyacid matrix of conventional glass-ionomer ${ }^{15}$. The setting reaction of these materials includes a radical chain polymerization and an acid base cross-linking reaction. The polymerization can be produced by either a chemical mechanism, with a thermal activated initiator, a photochemical mechanism with a photoinitiator activated by visible light (usually in the 400-500 $\mathrm{nm}$ wavelength range), or simultaneous presence of both initiators ${ }^{16}$. The dual setting system is expected to enhance the physical and mechanical properties of the glass ionomer. In particular, the polymerization reaction should avoid the early moisture sensitivity ${ }^{15}$.

Despite the composition enhancement, a previous study ${ }^{5}$ showed that RMGIC specimens photoactivated with a LED unit presented significantly more water sorption than those polymerized with a halogen light. The higher sorption of specimens due to a lower polymerization may interfere negatively with the mechanical and esthetic properties of RMGIC restorations. Different methods have been applied for evaluation of the quality of polymerization of resin-based materials ${ }^{10,11}$. Among these methods, microhardness test has been used in several works for the indirect study of resinbased materials polymerization and the evaluation of curing unit efficiency ${ }^{9,12,13,25,27}$.

The purpose of this study was to assess the microhardness of two RMGICs photoactivated with a LED source. The results were compared to values obtained when a halogen curing unit was used. A commercial resin composite was used as a restorative material control group. The first null hypothesis to be tested was that the microhardness values seen at the top surface when the LED is used are similar to the values obtained when the QTH is used. The second null hypothesis was that the values seen at the bottom surface when the LED is used are similar to those obtained when the QTH is used. The third null hypothesis to be tested was that there is no difference in the microhardness values when the microhardness values at the top surface are compared to those seen at the bottom surface, irrespective of the tested restorative material (two RMGICs and a resin composite).

\section{MATERIAL AND METHODS}

Two commercial RMGICs [Fuji II LC Improved, GC, Alsip, IL, USA (RM1), and Vitremer, 3M ESPE, St Paul, MN, USA, (RM2)] were tested in this study. A commercial resin composite [Filtek Z250, 3M ESPE (RM3)] was used as restorative material control. Shade A3 was used for all materials. Materials were handled and photoactivated according to manufacturers' directions and inserted into stainless steel molds ( $2 \mathrm{~mm}$ thick, $3 \mathrm{~mm}$ diameter). A pilot study was conducted to calibrate the operator and to determine sample size. Restorative materials were photoactivated simulating the curing scenario in a $2.0-\mathrm{mm}$ deep preparation. In addition, the diameter of the specimens provided an adequate area for indentations.

After insertion, a polyester strip was applied to the surface of the unpolymerized materials and a microscope slide was pressed against the ring to adapt the materials completely to the inner portion of the ring. Not only the same restorative material volume was obtained, but also a flat top and bottom surfaces. The excess material was removed and the specimens were then photoactivated at the top surface. Two curing units were used to polymerize the specimens: a LED [Ultrablue IS, DMC Equipamentos Ltda., São Carlos, SP, Brazil] and a QTH [XL3000; 3M ESPE]. The power density of both light units was assessed with a hand-held radiometer (Curing Radiometer; Demetron Research Corp., Danbury, CT, USA). The power density was around $600 \mathrm{~mW} / \mathrm{cm}^{2}$. The exposure time for each material followed manufacturer's instructions. RM1 and RM3 were photoactivated for $20 \mathrm{~s}$, while RM2 was photoactivated for $40 \mathrm{~s}$. Cylindrical specimens were divided into 6 groups with five specimens each, according to the different restorative material/light-curing unit combinations used.

After photoactivation, the specimens were removed from the molds and the top surface was identified with an indelible mark. A single operator prepared the specimens. The specimens were then stored into lightproof recipients for $24 \mathrm{~h}$. After this period, the microhardness test was performed in a digital Knoop hardness-measuring instrument under load (Shimadzu HMV-M Microhardness Tester; Newage Testing instruments Inc., Southampton, PA, USA). Six randomized indentations ( 3 on both the top and bottom surfaces) were made with a $25 \mathrm{~g}$ load for $30 \mathrm{~s}$, with a dwell time of $15 \mathrm{~s}$. For randomization, specimens were arbitrarily rotated before indentations. Calculations were made using computer software (C.A.M.S., Automated Microhardness Tester System, Newage Testing instruments, Inc., Southampton, PA, USA).

\section{Statistical Analysis}

Statistical analysis was made using a three-way ANOVA and the Tukey-Kramer post hoc test for pair-wise comparisons. All statistical testing was performed at a preset alpha of 0.05 . Three-way ANOVA was performed to evaluate the influence of the three variables tested: lightcuring units, restorative materials and surface (top and bottom). The software employed was SAS/STAT System, v.8.2 (SAS Institute Inc., Cary, NC, USA).

\section{RESULTS}

Table 1 presents the microhardness mean values (standard deviation) of the top and the bottom surfaces. At the top surface, RM1 presented the highest microhardness mean value $(95.3 \pm 5.2)$ when the LED light was used, whereas RM2 presented the lowest mean value $(70.8 \pm 6.8)$. Statistical analysis showed no statistically significant difference $(p>0.05)$ in the microhardness mean values, irrespective of the light-curing unit used to polymerize the restorative materials.

At the bottom surface, the LED light produced the highest hardness mean value for RM1 $(100.1 \pm 1.7)$ and the 
TABLE 1- Mean microhardness (standard deviation) values of studied groups

\begin{tabular}{|c|c|c|}
\hline Groups & Top & Bottom \\
\hline Fuji (RM1) + Halogen & $89.39(5.81)^{a, b^{*}, A^{* *}}$ & $84.85(5.6)^{a, A}$ \\
\hline Fuji (RM1) + LED & $95.25(5.16)^{a, b, A}$ & $100.10(1.65)^{\mathrm{b}, \mathrm{A}}$ \\
\hline Vitremer (RM2) + Halogen & $80.33(7.24)^{\mathrm{b}, \mathrm{d}, \mathrm{A}}$ & $80.56(6.72)^{\mathrm{a}, A}$ \\
\hline Vitremer (RM2) + LED & $70.83(6.83)^{\mathrm{d}, \mathrm{A}}$ & $61.05(4.21)^{\mathrm{c}, \mathrm{A}}$ \\
\hline Z250 (RM3) + Halogen & $84.59(5.74)^{a, b, c, A}$ & $67.27(4.24)^{\mathrm{c}, \mathrm{B}}$ \\
\hline Z250 (RM3) + LED & $81.83(4.29)^{b, c, d, A}$ & $66.95(5.91)^{\mathrm{c}, \mathrm{B}}$ \\
\hline
\end{tabular}

*similar lower case letters in each column indicate no statistically significant difference between groups.

**similar upper case letters in each line indicate no statistically significant difference between top/bottom.

lowest for RM2 (61.1 \pm 4.2$)$. The microhardness of RM2 was significantly higher $(\mathrm{p}<0.05)$ when the QTH was used compared with when the LED was used. On the other hand, at the same surface, there was significantly lower microhardness mean value for RM1 when the QTH was used compared to the mean value obtained when the LED unit was used $(\mathrm{p}<0.05)$. Regarding the microhardness mean values of RM3 at the bottom surface, no significantly difference $(p>0.05)$ was seen when the curing lights were compared $(67.3 \pm 4.2$ for the QTH, and $66.9 \pm 5.9$ for the LED).

The top-to-bottom variation in the microhardness mean values for each material/curing unit combination was also evaluated. No statistically significant difference was found when both RMGICs were polymerized either with the QTH or the LED ( $p>0.05)$. For the RM3, the microhardness at the top surface was significantly higher than the values seen at the bottom surface for both curing units $(p<0.05)$. Statistical analysis also demonstrated that the interaction material $x$ light-curing unit $x$ surface significantly influenced on the microhardness values $(\mathrm{p}=0.0142)$.

\section{DISCUSSION}

The first hypothesis, that the microhardness values seen at the top surface when the LED is used are similar to those obtained when the QTH is used, was validated. On the other hand, the second hypothesis, that the values seen at the bottom surface when the LED light is used is similar to the values when the QTH is used, was rejected. Only RM3 presented no significantly different values at the bottom surface. At the same surface, the microhardness mean value of RM2 (Vitremer) was significantly higher when the QTH was used $(80.33 \pm 7.24)$ compared to the LED values $(70.83$ \pm 6.83 for LED). For RM1 (Fuji II LC Improved), the opposite was seen. Significantly lower values were seen when the LED light was used $(89.39 \pm 5.81$ for QTH, and $95.25 \pm 5.16$ for LED).

To explain the results seen at the top and bottom surfaces, it is important to understand the polymerization process.
There is minimal light attenuation at the top, irradiated surface and the polymerization process proceeds very quickly because virtually all photoinitiator is activated ${ }^{24}$. Deeper in the resin-based photoactivated material, however, light attenuation and scattering cause a decrease in conversion as fewer molecules of camphorquinone are activated leading to a much reduced extent of reaction. ${ }^{6,22}$. Depending on the number of photons, less light will be able to penetrate to deeper depths of restorative material, decreasing the probability of raising a large number of photoabsorbing molecules to the excited state, increasing total conversion ${ }^{22}$. In contrast, the values seen for RM1 (Fuji II LC Improved) did not follow the conventional polymerization process protocol. In a study using infrared spectrophotometer to evaluate the polymerization kinetics in resin-modified glass-ionomer dental cements ${ }^{29}$, it was found that there are various changes in the spectra of GC Fuji II LC Improved during the polymerization process. The author explained that, within only 1 min after a 20 -s long light exposure, the great majority of the monomers (approximately 90\%) is rapidly polymerized ${ }^{29}$.

One might expect similar microhardness values at the top and bottom surfaces for both RMGICs as an acid/glass reaction occurs into these materials simultaneously as the monomer conversion reaction (HEMA-based materials) ${ }^{29}$. It is expected that this reaction occurs continuously at low speed over $24 \mathrm{~h}^{18,29}$. According to the results of the present study, it can be inferred that the hardness values of both RMGICs were dependent on the light used to polymerize them. The LED provided an additional polymerization at both the top and bottom surfaces for the RMGIC Fuji II LC Improved.

RM2 (Vitremer) showed higher microhardness values when the QTH was used in comparison to when the LED was used. LED units generate high power density over a narrow spectral region within which camphorquinone is known to abundantly absorb energy ${ }^{23}$. On the other hand, QTH are known to emit a comparatively wider spectral range, covering even more of the region in which camphorquinone absorbs ${ }^{23}$. According to manufacturer's information (Vitremer Technical Profile, 1992), RM2 is a 
camphorquinone-, HEMA-based restorative material. The reason to explain the higher values seen when the QTH polymerize this material can be related to the heating delivered by this light curing unit ${ }^{21}$. Lovell, et al. ${ }^{14}$ pointed out that a greater monomer conversion would be caused by a combination of both light energy and thermal effects. In a study ${ }^{28}$, comparing the heating of two commercial curing lights (first-generation LED and a conventional QTH) with similar power densities (approximately $600 \mathrm{~mW} / \mathrm{cm}^{2}$ ), it was found that the halogen light delivered three times more heating than that produced by the LED units. In the present study, the exposure time used to photoactivate the tested materials was different. The exposure time for RM2 was two times longer than the time used to polymerize RM1 (20 s for Fuji II LC Improved, and 40s for Vitremer). The heating caused by the QTH light during a 40-s exposure might have helped RM2 to obtain quite identical microhardness values both at the top and bottom surfaces $(80.3 \pm 7.3$, and $80.7 \pm$ 6.7 , respectively).

The third null hypothesis, that there is no difference in the microhardness values when the microhardness values at the top surface compared with the values seen at the bottom surface, was rejected. Comparing the values seen at the top and bottom surfaces, no significantly difference was seen for both RMGICs. In contrast, for RM3, the microhardness values seen at the top surface were statistically significant $(\mathrm{p}<0.05)$ for both light units compared to mean values seen at the bottom surface. The reason for the top-to-bottom difference in the microhardness values for the resin composite is also explained considering the polymerization process, in the same way as previously described ${ }^{22}$.

The similar microhardness values seen at the top and bottom surfaces for both RMGICs can be also explained because of the acid/glass reaction that occurs into these materials simultaneously the monomer conversion polymerization process to and continues slowly after clinical setting ${ }^{7}$. Additionally, two types of setting reactions take place in the light cured glass ionomer: (1) the acid-base reaction between the fluoroaluminosilicate glass and the polycarboxylic acid, the same reaction as in a conventional glass ionomer, and (2) a light-activated free radical polymerization of methacrylate groups of the polymer and HEMA (2-hydroxyethylmethacrylate) ${ }^{18,29}$. Since the rate of the second reaction, the photo-polymerization reaction, is much faster than the first, the setting time of the cement is much shorter than that of conventional systems ${ }^{7}$. This curing reaction gives these materials extended working time and optimal physical properties ${ }^{18}$. It somehow guaranties, after a 24-h time period, the almost complete homogeneity of the microhardness values throughout the specimens seen in the present study.

The clinical significance of the present work is that it is important to understand the acid/glass reaction and the polymerization process to appropriately place resinmodified glass-ionomer cement restorations. It was also demonstrated that, using different light-curing units, the results seen in the different restorative materials tested was completely different.

\section{CONCLUSIONS}

Within the limitations of this study, the following conclusions may be drawn:

- At the top surface, the microhardness of resin modified glass-ionomer cements was not influenced by the curing light used (hypothesis 1 accepted);

- At the bottom surface, the use of different light-curing units to polymerize both resin modified glass-ionomer cements influenced the microhardness values (hypothesis 2 rejected)

- For the tested resin-modified glass ionomer cements, the hardness values seen at the bottom surface were similar compared to that observed at the top surface. For the resin composite. Lower microhardness values were found at the bottom surface (hypothesis 3 rejected).

\section{REFERENCES}

1-Araujo CS, Schein MT, Zanchi CH, Rodrigues SA Jr, Demarco FF. Composite resin microhardness: the influence of light curing method, composite shade, and depth of cure. J Contemp Dent Pract. 2008;9(4):4350 .

2-Bala O, Olmez A, Kalayci S. Effect of LED and halogen light curing on polymerization of resin-based composites. J Oral Rehabil. 2005;32(2):13440 .

3-Bouillaguet S, Caillot G, Forchelet J, Cattani-Lorente M, Wataha JC, Krejci I. Thermal risks from LED- and high-intensity QTH-curing units during polymerization of dental resins. J Biomed Mater Res. 2005;72(2):260-7.

4-Cavalcante LM, Peris AR, Ambrosano GM, Ritter AV, Pimenta LA. Effect of photoactivation systems and resin composites on the microleakage of esthetic restorations. J Contemp Dent Pract. 2007;8(2):709.

5-Cefaly DF, Wang L, Mello LL, Santos JL, Santos JR, Lauris JR. Water sorption of resin-modified glass-ionomer cements photoactivated with LED. Braz Oral Res. 2006;20(4):342-6.

6-Davidson-Kaban SS, Davidson CL, Feilzer AJ, Gee AJ, Erdilek N. The effect of curing light variations on bulk curing and wall-to-wall quality of two types and various shades of resin composites. Dent Mater. 1997;13(6):344-52.

7-Della Bona A, Pinzetta C, Rosa V. Effect of acid etching of glass ionomer cement surface on the microleakage of sandwich restorations. J Appl Oral Sci. 2007;15(3):230-4.

8-Dunn WJ, Bush AC. A comparison of polymerization by light-emitting diode and halogen-based light-curing units. J Am Dent Assoc. 2002;133(3):335-41.

9-Ellakuria J, Triana R, Minguez N, Soler I, Ibaseta G, Maza J, et al. Effect of one-year water storage on the surface microhardness of resinmodified versus conventional glass-ionomer cements. Dent Mater. 2003;19(4):286-90.

10-Ferracane JL, Berge HX. Fracture toughness of experimental dental composites aged in ethanol. J Dent Res. 1995;74(7):1418-23.

11-Ferracane JL, Mitchem JC, Condon JR, Todd R. Wear and marginal breakdown of composites with various degrees of cure. J Dent Res. 1997;76(8):1508-16. 
12-Gomes GM, Calixto AL, Santos FA, Gomes OM, D'Alpino PH, Gomes JC. Hardness of a bleaching-shade resin composite polymerized with different light-curing sources. Braz Oral Res. 2006;20(4):337-41.

13-Kurachi C, Tuboy AM, Magalhaes DV, Bagnato VS. Hardness evaluation of a dental composite polymerized with experimental LEDbased devices. Dent Mater. 2001;17(4):309-15.

14-Lovell LG, Newman SM, Donaldson MM, Bowman CN. The effect of light intensity on double bond conversion and flexural strength of a model, unfilled dental resin. Dent Mater. 2003;19(6):458-65.

15-Mathis RS, Ferracane JL. Properties of a glass-ionomer/resin-composite hybrid material. Dent Mater. 1989;5(5):355-8.

16-Micelli F, Maffezzoli A, Terzi R, Luprano VA. Characterization of the kinetic behavior of resin modified glass-ionomer cements by DSC, TMA and ultrasonic wave propagation. J Mater Sci Mater Med. 2001;12(2):1516.

17-Miyazaki M, Hattori T, Ichiishi Y, Kondo M, Onose H, Moore BK. Evaluation of curing units used in private dental offices. Oper Dent. $1998 ; 23(2): 50-4$

18-Mount GJ, Patel C, Makinson OF. Resin modified glass-ionomers strength, cure depth and translucency. Aust Dent J. 2002;47(4):339-43.

19-Okte Z, Villalta P, Garcia-Godoy F, Garcia-Godoy F, Jr., Murray P. Effect of curing time and light curing systems on the surface hardness of compomers. Oper Dent. 2005;30(4):540-5.

20-Price RB, Ehrnford L, Andreou P, Felix CA. Comparison of quartztungsten-halogen, light-emitting diode, and plasma arc curing lights. J Adhes Dent. 2003;5(3):193-207.

21-Rafeek RN. The effects of heat treatment on selected properties of a conventional and a resin-modified glass ionomer cement. J Mater Sci Mater Med. 2008;19(5):1913-20.

22-Rueggeberg F. Contemporary issues in photocuring. Compend Contin Educ Dent. 1999;25:S4-S15.

23-Rueggeberg FA, Blalock JS, Callan RS. LED curing lights - what's new? Compend Contin Educ Dent. 2005;26(8):586, 588, 590-1.

24-Rueggeberg FA, Caughman WF, Curtis JW Jr, Davis HC. Factors affecting cure at depths within light-activated resin composites. Am J Dent. 1993;6(2):91-5.

25-Soh MS, Yap AU, Siow KS. The effectiveness of cure of LED and halogen curing lights at varying cavity depths. Oper Dent. 2003;28(6):70715

26-Tolosa MC, Paulillo LA, Giannini M, Santos AJ, Dias CT. Influence of composite restorative materials and light-curing units on diametrical tensile strength. Braz Oral Res. 2005;19(2):123-6.

27-Uhl A, Sigusch BW, Jandt KD. Second generation LEDs for the polymerization of oral biomaterials. Dent Mater. 2004;20(1):80-7.

28-Yap AU, Soh MS. Thermal emission by different light-curing units. Oper Dent. 2003;28(3):260-6.

29-Young AM. FTIR investigation of polymerization and polyacid neutralization kinetics in resin-modified glass-ionomer dental cements. Biomaterials. 2002;23(15):3289-95. 